\title{
Comparative Analysis of Two Flap Designs for the Extraction of Impacted Mandibular Horizontal Third Molars: a Multicenter Randomized Control Trial
}

\author{
Nagasaki University

\section{Satoshi Rokutanda} \\ Juko Memorial Nagasaki Hospital \\ Satoshi Inokuchi \\ Omura Municipal Hospital \\ Keisuke Omori \\ Nagasaki University \\ Souichi Yanamoto \\ Nagasaki University \\ Masahiro Umeda \\ Nagasaki University
}

Tomofumi Naruse ( $\square$ naruse12@nagasaki-u.ac.jp )

\section{Research Article}

Keywords: impacted mandibular third molar, modified envelope flap, triangular flap, extraction, randomized control trial

Posted Date: September 17th, 2021

DOl: https://doi.org/10.21203/rs.3.rs-877783/v1

License: (c) (1) This work is licensed under a Creative Commons Attribution 4.0 International License. Read Full License 


\section{Abstract}

Most patients experience postoperative complications caused by the extraction of impacted mandibular horizontal third molars. The aim of the present study was to compare the effects of two flap designs as a refinement on the reduction of postoperative complications. One hundred eighty-eight patients with impacted mandibular horizontal third molars were included in this single-blind, multicenter, randomized control trial. The allocation was determined using a modified envelope flap (mEF) and triangular flap (TF) at $1: 1$ by the data manager. Postoperative complications (pain, hemorrhage, nerve paralysis, dry socket, and infection) and operation time were assessed $7 \pm 1$ days after surgery. In all cases, postoperative pain was significantly lower in the $\mathrm{mEF}$ group $(P<0.05)$. In the subgroup analysis, postoperative pain was significantly lower in patients with low difficulty (IA, IIA, IIA, IB), which were classified by G.B. Winter classification $(P<0.05)$. Other factors were not significantly associated with the flap design. Our study suggests that $\mathrm{mEF}$ resulted in less postoperative pain with a low difficulty of impacted mandibular horizontal third molars. However, the evidence at present is not sufficient to suggest the use of either flap design.

\section{Introduction}

Extraction of impacted mandibular horizontal third molars is the most common surgery performed by oral surgeons. Surgical procedures may vary depending on the flap design and cutting instrument, with or without the drainage or suturing technique ${ }^{[1-4]}$, but most oral surgeons may experience the extraction on the basis of the instructor's procedure. Therefore, the advantages or disadvantages of the surgical procedure are rarely analyzed systematically. Extraction of impacted mandibular horizontal third molars frequently cause postoperative complications such as pain, swelling, hemorrhage, or nerve paralysis. Therefore, minimizing the postoperative complications experienced by patients are important for oral surgeons.

Several techniques for reducing postoperative complications have been reported on flap design, suture technique, and irrigation solution ${ }^{[5]}$. In this study, we focused on the flap design. Among the flaps employed for impacted mandibular horizontal third molars extraction ${ }^{[6-13]}$, triangular flap (TF) and envelope flap (EF) are the most widely applied and have been used in clinical trials that compared the two flaps ${ }^{[10,14-18]}$. Recently, the effectiveness of the modified envelope flap (mEF), which shortened the incision from the EF or TF without vertical incision has been advocated in our study group.

Intraoperatively, TF has the advantages of a wide surgical field and easy flap formation, as well as the disadvantage of increased invasive surgical procedure due to extension of the vertical incision to the buccal gum. Although mEF has the disadvantage of a small surgical field, it is unclear whether shortened incision contributes to the reduction of invasive surgical procedures and associated reduction of postoperative complications. In addition, as $\mathrm{mEF}$ has not been analyzed in the previous reports, the superiority of $\mathrm{mEF}$ is unclear. 
This multicenter randomized clinical trial (RCT) was conducted to examine the early postoperative complications in mandibular horizontal third molars and to compare the effects of the two flap designs. Achieving this goal will most likely suggest the usefulness of $\mathrm{mEF}$ with resultant reduced postoperative complications for patients and enhanced quality of life.

\section{Material And Methods}

\section{Ethics and Registration}

This study was was approved by the independent ethics committee of all participating hospitals (Chief institution: Omura Municipal Hospital: approval No. 31) and, is registered at the University hospital Medical Information Network Clinical Trials Registry (UMIN000045413:07/09/2021). All methods were carried out in accordance with relevant guidelines and regulations' or the 'Declaration of Helsinki

\section{Study design}

This study was a multicenter, single-blind (participant), RCT. The study participants were allocated to a mEF group or TF group using a simple randomization. The inclusion criteria were patients: (1) 20 years or older with impacted mandibular horizontal third molars under local anesthesia in outpatients; (2) with an indication for the extraction of impacted mandibular horizontal third molars; and (3) signed informed consent form for participation and permission to use the obtained data for research purposes. Exclusion criteria were patients: (1) with deficiency of the mandibular second molars; (2) taking an anticancer drug, an immunosuppressive drug, or an antithrombotic drug; and (3) with a systemic disease that prevents surgery. Patients who met the criteria mentioned above between January and December 2020 were enrolled in the study at Omura municipal hospital and Juko Memorial Nagasaki Hospital. The allocation was determined as $\mathrm{MEF}$ and TF at 1:1 by the data manager. The allocation factor was set as low

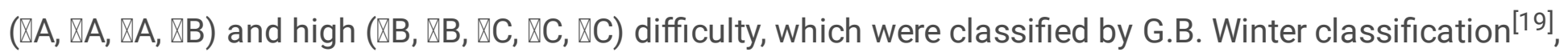
and difficulty was allocated equally in both groups.

\section{Surgical procedure}

All operations were performed by two oral surgeons with board certification for the specialist and two oral surgeons with board certification for the semi-specialist in Japanese Society of Oral and Maxillofacial Surgeons. The surgical procedure of $\mathrm{mEF}$ starts with the rise of the mandibular ramus, following alveolar ridges of the third molar and gingival buccal sulcular incision to the mesial of the second molar (Fig 1A). The surgical procedure of TF adds a vertical incision to the buccal gum in addition to the $\mathrm{mEF}$ procedure (Fig 1B). All cases of extraction were performed in the way of each surgeon other than the flap. If the flap was torn by flap retractor and $\mathrm{mEF}$ became TF-like, the analysis was performed with $\mathrm{mEF}$ according to intention-to-treat analysis. After extraction, oxytetracycline hydrochloride and absorbable gelatin sponge (Spongel ${ }^{\circledR}$ ) were inserted into the socket. The suture method was one stitch on the distal gum of the second molar in $\mathrm{mEF}$, and one stitch each on the distal and buccal gum of the second molar in TF. The antimicrobial agent was administered three times a day with amoxicillin $250 \mathrm{mg}$ for two days, and 
analgesic was administered three times a day with $60 \mathrm{mg}$ loxoprofen for seven days. Postoperative complications were evaluated $7 \pm 1$ days after the operation.

\section{Endpoint}

The primary endpoint of the study was the difference in the postoperative complications (postoperative pain, hemorrhage, paralysis of the inferior dental nerve, dry socket, and infection) between mEF and TF. Postoperative pain was evaluated using a visual analog scale (VAS) ranging from 0 (no pain) to 10 (worst pain). The VAS variables were categorized as no pain (0), mild pain (1-4), moderate pain (5-7) and severe pain (8-10). Postoperative hemorrhage was divided into three grades: Grade 1: hemostasis was performed with pressure alone; Grade 2: hemostasis requiring additional surgical treatment, such as hemostat or re-suturing; Grade 3: hemostasis requiring systemic treatment, such as vitamin $\mathrm{K}$ or freshfrozen plasma ${ }^{[20]}$. Postoperative hemorrhage was determined to be more grade 1. A diagnosis of paralysis of the inferior dental nerve was determined by a doctor when the patient reported nerve paralysis. A diagnosis of dry socket was determined by the doctor who had performed the surgery when the patient reported spontaneous post-extraction pain that did not subside after 1 to 3 days. The pus from the extracted socket was diagnosed as a postoperative infection. The secondary endpoint of the study was the difference in the operation time. The operation time was determined as the duration from the incision of the gum, tooth extraction, and suture of the gum.

\section{Statistical analysis}

All statistical analyses were performed using SPSS version 24.0 (Japan IBM Co., Tokyo, Japan). Univariate analyses between clinical comparisons of categorical variables were performed using Fisher's exact test. Differences in the average values of operation times between the two groups were compared using the non-parametric Mann-Whitney U-test. Statistical significance was set at $P<0.05$.

\section{Results}

\section{Characteristics of the patients}

A total of 190 patients were enrolled in the study and randomized to one of the two flap designs. Two patients withdrew because of difficulty in hospital visits after extraction, as shown in the CONSORT flow diagram (Fig. 2). A total of 188 patients completed the study protocol. Characteristics of the patients are shown in Table 1. Seventy-five patients were men and 113 were women. The median age of the patients was 31.3 years (range, 20-75 years). Eighty-one patients were drinkers, 31 patients were smokers, 3 patients had hypertension, and none had diabetes mellitus. A total of 129 patients had a root apex of the third molar close to the mandibular canal $(<2 \mathrm{~mm})$ in panoramic X-ray findings. The impacted mandibular horizontal third molars of 122 patients were classified as having low difficulty according to the G.B. Winter classification. 
Table 1

Patients characteristics

\begin{tabular}{|c|c|}
\hline Number of patients & 188 \\
\hline Age, years, mean (range) & $31.3(20-75)$ \\
\hline \multicolumn{2}{|l|}{ Sex, n (\%) } \\
\hline Male & $75(39.9)$ \\
\hline Female & $113(60,1)$ \\
\hline \multicolumn{2}{|l|}{ Drinking, n (\%) } \\
\hline No & $10756.9)$ \\
\hline Yes & $81(43.1$ \\
\hline \multicolumn{2}{|l|}{ Smoking, n (\%) } \\
\hline No & $157(83.5)$ \\
\hline Yes & $31(16.5)$ \\
\hline \multicolumn{2}{|l|}{ Hypertension, n (\%) } \\
\hline No & $185(98.4)$ \\
\hline Yes & $3(1.6)$ \\
\hline \multicolumn{2}{|l|}{ Diabetes mellitus, $\mathrm{n}(\%)$} \\
\hline No & $0(0)$ \\
\hline Yes & $188(100)$ \\
\hline \multicolumn{2}{|c|}{ Root apex and mandibular canal, n (\%) } \\
\hline Intact & $59(31.4)$ \\
\hline Contact & $129(68.6)$ \\
\hline \multicolumn{2}{|c|}{ G.B. Winter classification, $\mathrm{n}(\%)$} \\
\hline Low & $122(64.9)$ \\
\hline High & $66(35.1)$ \\
\hline \multicolumn{2}{|c|}{ 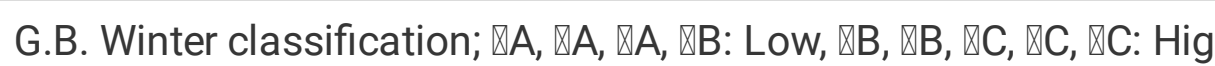 } \\
\hline
\end{tabular}

\section{Comparison of postoperative complications between $\mathrm{mEF}$ and TF}

The background factors that may affect postoperative complications were equally allocated to each group (Table 2). In all cases, postoperative pain was significantly lower in the mEF group. Other factors 
were not significantly associated with flap design. The use of $\mathrm{mEF}$ can save about one minute compared to TF, but there was no significant difference (Table 3). In the subgroup analysis of low and high difficulty, postoperative pain was significantly lower in $\mathrm{mEF}$ with low difficulty (Table 4), while no significant difference was observed in both flaps with high difficulty (Table 5). Other factors were also not significantly associated with the flap design. Postoperative hemorrhage was observed in 30 cases, all of which were grade 1 , not more grade 2 . Taken together, less postoperative pain used by mEF was significantly suggested in low difficult impacted mandibular horizontal third molars, whereas there was no significant difference in the highly difficult impacted mandibular horizontal third molar. The usefulness of mEF was confirmed in statistical analysis, so the number of patients recruited was considered to be adequate.

Table 2

Comparison of background factors between $\mathrm{MEF}$ and TF

\begin{tabular}{|c|c|c|c|c|c|}
\hline Factor & & $\mathrm{n}$ & $\mathrm{mEF}$ & TF & $p$ value \\
\hline \multirow[t]{2}{*}{ Age } & $32>$ & 100 & 52 & 58 & \multirow[t]{2}{*}{0.459} \\
\hline & $32 \leqq$ & 88 & 42 & 36 & \\
\hline \multirow[t]{2}{*}{ Sex } & Male & 75 & 42 & 33 & \multirow[t]{2}{*}{0.184} \\
\hline & Female & 113 & 52 & 61 & \\
\hline \multirow[t]{2}{*}{ Drinking } & No & 107 & 53 & 54 & \multirow[t]{2}{*}{1.000} \\
\hline & Yes & 81 & 41 & 40 & \\
\hline \multirow[t]{2}{*}{ Smoking } & No & 157 & 79 & 78 & \multirow[t]{2}{*}{1.000} \\
\hline & Yes & 31 & 15 & 16 & \\
\hline \multirow[t]{2}{*}{ Hypertension } & No & 185 & 93 & 92 & \multirow[t]{2}{*}{1.000} \\
\hline & Yes & 3 & 1 & 2 & \\
\hline \multirow[t]{2}{*}{ Diabetes mellitus } & No & 188 & 94 & 94 & \multirow[t]{2}{*}{1.000} \\
\hline & Yes & 0 & 0 & 0 & \\
\hline \multirow[t]{2}{*}{ Root apex and mandibular canal } & Intact & 59 & 31 & 28 & \multirow[t]{2}{*}{0.753} \\
\hline & Contact & 129 & 63 & 66 & \\
\hline \multirow[t]{2}{*}{ G.B. Winter classification } & Low & 122 & 61 & 61 & \multirow[t]{2}{*}{1.000} \\
\hline & High & 66 & 33 & 33 & \\
\hline
\end{tabular}


Table 3

Comparison of postoperative complications between $\mathrm{mEF}$ and TF in all cases

\begin{tabular}{|c|c|c|c|c|c|}
\hline Factor & & $\mathbf{n}$ & $\mathrm{mEF}$ & TF & $p$ value \\
\hline Operation time & mean $(\min )$ & 188 & 15.745 & 16.681 & 0.422 \\
\hline \multirow[t]{2}{*}{ Hemorrhage } & No & 158 & 80 & 78 & \multirow[t]{2}{*}{0.843} \\
\hline & Yes & 30 & 14 & 16 & \\
\hline \multirow[t]{2}{*}{ Nerve paralysis } & No & 188 & 94 & 94 & \multirow[t]{2}{*}{1.000} \\
\hline & Yes & 0 & 0 & 0 & \\
\hline \multirow[t]{2}{*}{ Pain } & None, Mild & 121 & 68 & 53 & \multirow[t]{2}{*}{0.033} \\
\hline & Moderate, Severe & 67 & 26 & 41 & \\
\hline \multirow[t]{2}{*}{ Dry socket } & No & 184 & 92 & 92 & \multirow[t]{2}{*}{1.000} \\
\hline & Yes & 4 & 2 & 2 & \\
\hline \multirow[t]{2}{*}{ Infection } & No & 174 & 89 & 85 & \multirow[t]{2}{*}{0.405} \\
\hline & Yes & 14 & 5 & 9 & \\
\hline
\end{tabular}


Table 4

Subgroup analysis in low difficulty between mEF and TF

\begin{tabular}{|c|c|c|c|c|c|}
\hline Factor & & $\mathrm{n}$ & $\mathrm{mEF}$ & TF & $p$ value \\
\hline Operation time & mean $(\min )$ & 122 & 13.385 & 14.689 & 0.48 \\
\hline \multirow[t]{2}{*}{ Hemorrhage } & No & 104 & 52 & 52 & \multirow[t]{2}{*}{1.000} \\
\hline & Yes & 18 & 9 & 9 & \\
\hline \multirow[t]{2}{*}{ Nerve paralysis } & No & 122 & 61 & 61 & \multirow[t]{2}{*}{1.000} \\
\hline & Yes & 0 & 0 & 0 & \\
\hline \multirow[t]{2}{*}{ Pain } & None, Mild & 83 & 49 & 36 & \multirow[t]{2}{*}{0.018} \\
\hline & Moderate, Severe & 39 & 12 & 25 & \\
\hline \multirow[t]{2}{*}{ Dry socket } & No & 121 & 61 & 60 & \multirow[t]{2}{*}{1.000} \\
\hline & Yes & 1 & 0 & 1 & \\
\hline \multirow[t]{2}{*}{ Infection } & No & 117 & 60 & 57 & \multirow[t]{2}{*}{0.364} \\
\hline & Yes & 5 & 1 & 4 & \\
\hline
\end{tabular}


Table 5

Subgroup analysis in high difficulty between $\mathrm{mEF}$ and TF

\begin{tabular}{|c|c|c|c|c|c|}
\hline Factor & & $\mathrm{n}$ & $\mathrm{mEF}$ & TF & $p$ value \\
\hline Operation time & mean $(\min )$ & 66 & 19.182 & 20.364 & 0.615 \\
\hline \multirow[t]{2}{*}{ Hemorrhage } & No & 54 & 28 & 26 & \multirow[t]{2}{*}{1.000} \\
\hline & Yes & 12 & 5 & 7 & \\
\hline \multirow[t]{2}{*}{ Nerve paralysis } & No & 66 & 33 & 33 & \multirow[t]{2}{*}{1.000} \\
\hline & Yes & 0 & 0 & 0 & \\
\hline \multirow[t]{2}{*}{ Pain } & None, Mild & 36 & 19 & 17 & \multirow[t]{2}{*}{0.805} \\
\hline & Moderate, Severe & 30 & 14 & 16 & \\
\hline \multirow[t]{2}{*}{ Dry socket } & No & 63 & 31 & 32 & \multirow[t]{2}{*}{1.000} \\
\hline & Yes & 3 & 2 & 1 & \\
\hline \multirow[t]{2}{*}{ Infection } & No & 57 & 29 & 28 & \multirow[t]{2}{*}{1.000} \\
\hline & Yes & 9 & 4 & 5 & \\
\hline
\end{tabular}

\section{Discussion}

Various flap designs that consider postoperative complications or periodontitis of the mandibular second molars have been reported. Among them, TF and EF are the most frequently used and have been examined ${ }^{[10,14-18]}$. The discussion proceeded with comparison with these reports and the effectiveness of $\mathrm{mEF}$ was clarified.

To the best of our knowledge, the strongest evidence of TF vs. EF has been reported in three systematic reviews and meta-analyses ${ }^{[15,17,18]}$. Among them, Zhu et al. ${ }^{[15]}$ reported that EF is more effective than TF in reducing postoperative pain and swelling in the subgroup with low difficulty. This is because tissue trauma, including vertical incision in the buccal gum, may lead to the release of local inflammatory mediators in TF and sensitize peripheral pain receptors in low difficulty ${ }^{[15]}$, resulting in more postoperative pain. However, as the invasive procedure of tooth extraction is greater in patients with high difficulty, the pain in the tissue trauma caused by vertical incision may not affect the postoperative pain ${ }^{[15]}$. Our results suggest that $\mathrm{mEF}$ is more effective in reducing postoperative pain in low difficulty cases. The significant difference was observed in all cases, because it may be a predilection in the number of low and high difficulty cases (2:1). Two other studies have reported that there was no significant difference between the two flaps ${ }^{[17,18]}$. As a problem of previous RCTs, most reports have shown that pain score was statistically evaluated using the mean VAS variables. The VAS is a universal instrument used to measure 
pain. However, as the VAS is an ordinal scale, not a ratio scale, a statistical method that compares the mean VAS variables is incorrect. For an ordinal scale, variables should be categorized into two groups and evaluated using Fischer's exact test or chi-square test. Therefore, most previous results related to postoperative pain should be interpreted with caution. To the best of our knowledge of the two studies with correct statistical analysis, Sandhu et al. ${ }^{[21]}$ reported that pain was significantly greater in EF compared with TF on postoperative day 1 and day 7 , while Xie et al. ${ }^{[22]}$ reported that there was no significant difference between $\mathrm{mEF}$ and TF. However, both studies were single-center and had a small number of cases. Moreover, as background factors related to patients, such as smoking and drinking, or difficulty of tooth extraction were unclear, there may be some confounding factors in these studies. Our results suggest that postoperative pain was significantly lower in $\mathrm{MEF}$ than in TF, which is different from the results of the previous two studies. The management of our multicenter RCT has been made uniform to control for confounding factors, and the results of our study must be strong evidence. Taken together, tissue trauma caused by vertical incision led to enhanced postoperative pain and $\mathrm{mEF}$ is more effective in reducing postoperative pain in low difficulty cases.

On the other hand, Zhu et al. ${ }^{[15]}$ reported that TF was more effective than EF in lowering the incidence of dry socket. Two other studies have reported that there was no significant difference between the two flaps ${ }^{[17,18]}$. However, no previous reports have histologically discussed the reasons for the lower incidence of dry socket in TF than in EF. The risk factors of dry socket have been associated with tobacco use, the amount of anesthesia, menstrual cycles, older patient age, surgical difficulty, and some drugs ${ }^{[23]}$. For this reason, Zhu et al. ${ }^{[15]}$ stated that their results should be interpreted carefully and analyzed accurately in a split-mouth controlled study. Elo et al. ${ }^{[24]}$ reported that mEF was more effective than TF and EF in lowering the incidence of dry socket in split-mouth controlled study This study had a large number of cases and had one of the strongest evidence in the previous reports. Our study suggests that there was no significant difference between the two groups. However, our study was a parallel randomized controlled trial with a small number of dry socket. Therefore, our findings should be interpreted with caution.

There were no significant differences in postoperative hemorrhage, nerve paralysis, and infection between the two groups. Flap design was not a critical factor for the improvement of complications. Mobilio et al. ${ }^{[14]}$ reported that operation time was the most important factor for early postoperative outcomes in the third molar extraction. Although there was no significant difference in operation time, the use of mEF can save approximately one minute compared to TF. To enclose the mesial vertical incision, one stitch is needed, leading to a longer operation time. Although $\mathrm{mEF}$ has the disadvantage of a small surgical field, there was no difference in operation time. Trismus and swelling are among the most important postoperative complications of the third molar extraction. Xie et al. ${ }^{[22]}$ reported that $\mathrm{mEF}$ was more effective than TF in reducing postoperative trismus on postoperative day 3 and 7 . In this study, postoperative pain, swelling and trismus were compared on days 3 and 7 after surgery. In all participating hospitals of our study, the postoperative examination was performed only on day $7 \pm 1$ after surgery. As 
detailed examinations on postoperative days 1, 3, and 7 could not be performed, evaluations of trismus and swelling were excluded.

This study has some potential limitations. The sample size was small, and the observation interval was short ( $7 \pm 1$ days). Early postoperative pain was significantly lower in the $\mathrm{mEF}$ group, but the long-term outcome (two or three weeks later) was unclear. Moreover, it was unclear whether mEF is better than TF in terms of periodontitis of the mandibular second molar. Therefore, multicenter RCTs with more participants and long-term follow-up are required in the future.

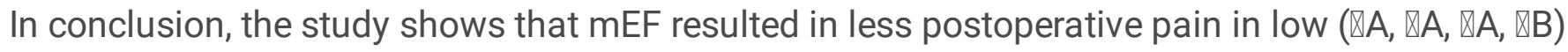

difficulty classified by G.B. Winter classification. This is because tissue trauma caused by vertical incision led to enhanced early postoperative pain in low difficulty cases. Although mEF has the disadvantage of a small surgical field, there is no bad influence in operation time. However, the evidence at present is not sufficient to suggest the use of either flap design.

\section{Declarations}

\section{Acknowledgement}

We greatly appreciate all patients who participated in this trial.

\section{Funding}

None declared

\section{Competing interests}

None declared.

\section{Ethical approval}

The study was approved by the independent ethics committee of all participating hospitals (Chief institution: Omura Municipal Hospital: approval No. 31).

\section{Author contributions}

All authors contributed to the conception and design of the study. Tooth extraction was performed by TN, $\mathrm{SR}, \mathrm{SI}$, and KO. Data analysis was performed by TN, SY and MU. The first draft of the manuscript was written by $\mathrm{TN}$, and all the authors commented on the previous versions of the manuscript. All authors read and approved the final manuscript.

\section{Data availability}

All data generated or analyzed during this study are included in this published article. 


\section{References}

1. Katz, M. S. et al. Effect of drain application on postoperative complaints after surgical removal of impacted wisdom teeth - A randomized observer-blinded split-mouth clinical trial. Clin. Oral Investig. 25, 345-353 (2021). 10.1007/s00784-020-03464-5.

2. Mistry, F. K., Hegde, N. D. \& Hegde, M. N. Postsurgical consequences in lower third molar surgical extraction using micromotor and piezosurgery. Ann. Maxillofac. Surg. 6, 251-259 (2016). 10.4103/2231-0746.200334.

3. Ramkumar Ceyar, K. A. et al. Effectiveness of knotless suture as a wound closure agent for impacted third molar-A split mouth randomized controlled clinical trial. J. Craniomaxillofac. Surg. 48, 10041008 (2020). 10.1016/j.jcms.2020.07.014.

4. Alkadi, S. \& Stassen, L. Effect of one-suture and sutureless techniques on postoperative healing After third molar surgery. J. Oral Maxillofac. Surg. 77, 703.e1-703.e16 (2019).

10.1016/j.joms.2018.12.001.

5. Ghosh D, et al. Comparison of efficacy of ozonated water, normal saline, and povidone-iodine after surgical removal of impacted mandibular third molars: A cross-sectional study. J. Fam. Med. Prim. Care 25, 4139-4144 (2020). 10.4103/jfmpc.jfmpc_534_20

6. Yolcu, Ü \& Acar, A. H. Comparison of a new flap design with the routinely used triangular flap design in third molar surgery. Int. J. Oral Maxillofac. Surg. 44, 1390-1397 (2015). 10.1016/j.jom.2015.07.007.

7. Goldsmith, S. M., Silva, R. K. De, Tong, D. C. \& Love, R. M. Influence of a pedicle flap design on acute postoperative sequelae after lower third molar removal. Int. J. Oral Maxillofac. Surg. 41, 371-375 (2012). 10.1016/j.ijom.2011.08.006.

8. Kirtiloğlu, T., Bulut, E., Sümer, M. \& Cengiz, I. Comparison of 2 flap designs in the periodontal healing of second molars After fully impacted mandibular third molar extractions. J. Oral Maxillofac. Surg. 65, 2206-2210 (2007). 10.1016/j.joms.2006.11.029.

9. Silva JL, Jardim EC, dos Santos PL, Pereira FP, Garcia Junior IR, Poi WR. Comparative analysis of 2flap designs for extraction of mandibular third molar. J.Craniofac Surg. 22, 1003-1007 (2011).

10. Suarez-Cunqueiro, M. M., Gutwald, R., Reichman, J., Otero-Cepeda, X. L. \& Schmelzeisen, R. Marginal flap versus paramarginal flap in impacted third molar surgery: A prospective study. Oral Surg. Oral Med. Oral Pathol. Oral Radiol. Endod. 95, 403-408 (2003). 10.1067/moe.2003.84.

11. Hur, Y. \& Ogata, Y. Different flap designs have no impact on periodontal outcomes on second molars after impacted third-molar extraction. J. Am. Dent. Assoc. 148, 849-852 (2017).

10.1016/j.adaj.2017.07.024.

12. Silva, J. L. et al. Comparative analysis of 2-flap designs for extraction of mandibular third molar. J. Craniofac. Surg. 22, 1003-1007 (2011). 10.1097/SCS.0b013e3182101551.

13. Suarez-Cunqueiro MM, Gutwald R, Reichman J, Otero-Cepeda XL. Schmelzeisen R. Marginal flap versus paramarginal flap in impacted third molar surgery: a prospective study. Oral Surg Oral Med 
Oral Pathol Oral Radiol Endod 95, 403-408 (2003). 10.1067/moe.2003.84

14. Mobilio, N., Vecchiatini, R., Vasquez, M., Calura, G. \& Catapano, S. Effect of flap design and duration of surgery on acute postoperative symptoms and signs after extraction of lower third molars: A randomized prospective study. J. Dent. Res. Dent. Clin. Dent. Prospects 11, 156-160 (2017). 10.15171/joddd.2017.028.

15. Zhu, J. et al. Comparison of postoperative outcomes Between envelope and triangular flaps After mandibular third molar surgery: A systematic review and meta-analysis. J. Oral Maxillofac. Surg. 78, 515-527 (2020). 10.1016/j.joms.2019.11.026.

16. Erdogan, O., Tatlı, U., Üstün, Y. \& Damlar, I. Influence of two different flap designs on the sequelae of mandibular third molar surgery. Oral Maxillofac. Surg. 15, 147-152 (2011). 10.1007/s10006-0110268-7.

17. Lopes da Silva, B. C., Machado, G. F., Primo Miranda, E. F., Galvão, E. L. \& Falci, S. G. M. Envelope or triangular flap for surgical removal of third molars? A systematic review and meta-analysis. Int. J. Oral Maxillofac. Surg. 49, 1073-1086 (2020). 10.1016/j.jjom.2020.01.001.

18. Glera-Suárez, P., Soto-Peñaloza, D., Peñarrocha-Oltra, D. \& Peñarrocha-Diago, M. Patient morbidity after impacted third molar extraction with different flap designs. A systematic review and metaanalysis. Med. Oral Patol. Oral Cir. Bucal 25, e233-e239 (2020). 10.4317/medoral.23320.

19. Sridharan, G., Nakkeeran, K. P., Andavan, G. \& Raja V B, K. K. "Effects of flap modification on third molar extraction outcomes"-A randomised split mouth study. J. Oral Biol. Craniofac. Res. 10, 619-624 (2020). 10.1016/j.jobcr.2020.08.010.

20. Hasegawa, T. et al. The risk factors associated with postoperative hemorrhage after tooth extraction: A multi-center retrospective study of patients receiving oral antithrombotic therapy. Oral Maxillofac. Surg. 21, 397-404 (2017). 10.1007/s10006-017-0645-y.

21. Sandhu, A., Sandhu, S. \& Kaur, T. Comparison of two different flap designs in the surgical removal of bilateral impacted mandibular third molars. Int. J. Oral Maxillofac. Surg. 39, 1091-1096 (2010). 10.1016/j.ijom.2010.07.003.

22. Xie, Q., Wei, S., Zhou, N. \& Huang, X. Modified envelope flap, a novel incision design, can relieve complications after extraction of fully horizontal impacted mandibular third molar. J. Dent. Sci. 16, 718-722 (2021). 10.1016/j.jds.2020.06.022.

23. Taberner-Vallverdú, M., Sánchez-Garcés, M. Á. \& Gay-Escoda, C. Efficacy of different methods used for dry socket prevention and risk factor analysis: A systematic review. Med. Oral Patol. Oral Cir. Bucal 22, e750-e758 (2017). 10.4317/medoral.21705.

24. Elo, J. A., Sun, H. H. (Brian), Dong, F., Tandon, R. \& Singh, H. M. Novel incision design and primary flap closure reduces the incidence of alveolar osteitis and infection in impacted mandibular third molar surgery. Oral Surg. Oral Med. Oral Pathol. Oral Radiol. 122, 124-133 (2016).

10.1016/j.0ooo.2016.01.024

\section{Figures}



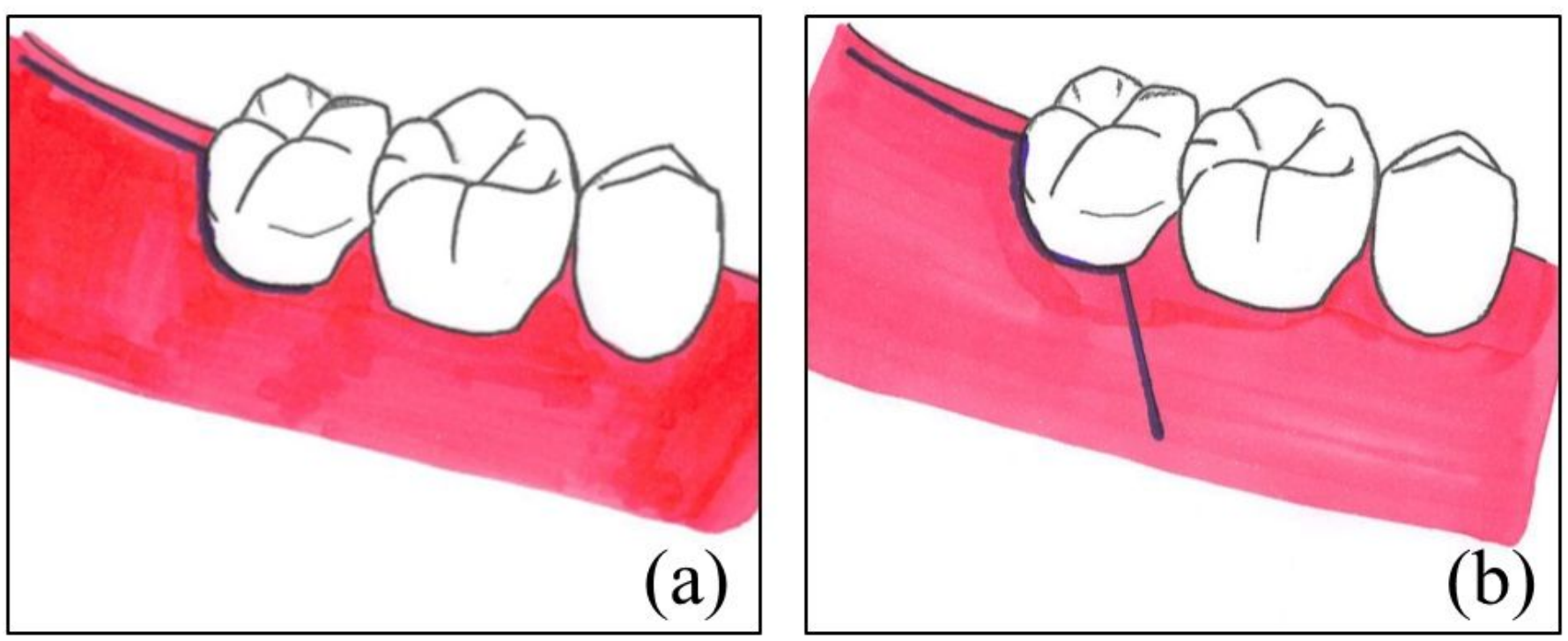

Figure 1

Surgical procedures of the modified envelope flap (A) and triangular flap (B) 


\section{Enrollment}

\section{Assessed for eligibility $(n=190)$}

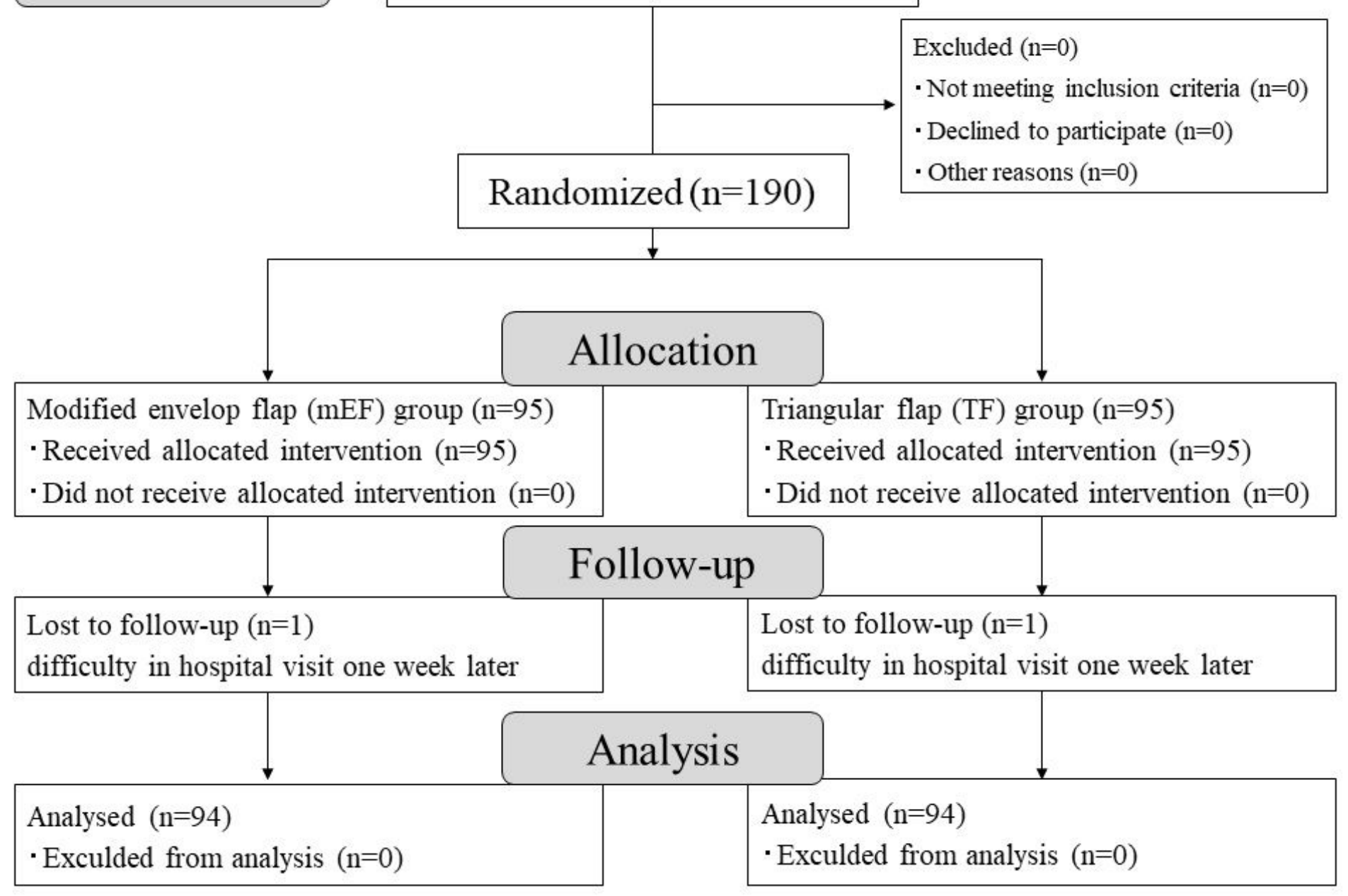

\section{Figure 2}

The CONSORT flow diagram 